\title{
Removal of Carcinogenic Arsenic from Drinking Water By the Application of lon Exchange Resins
}

\author{
Sevtap Karakurt ${ }^{1}$, Erol Pehlivan ${ }^{1}$ and Serdar karakurt ${ }^{2 *}$ \\ ${ }^{1}$ Department of Chemical Engineering, Technical University of Konya, Turkey \\ ${ }^{2}$ Department of Biochemistry, Faculty of Science, Selcuk University, Turkey
}

\section{*Corresponding author: \\ Serdar Karakurt}

Associate Professor, Department of Biochemistry,

Faculty of Science

Selcuk University, Konya, Turkey

Received : December 10, 2018

Published : January 19, 2019

\begin{abstract}
Cancer is the most common cause of the deaths and environmental pollutant is one of the main reasons for it. Within the scope of water intended for human consumption, trace arsenic concentration in drinking waters must be supplied below $10 \mu \mathrm{g} / \mathrm{L}$, in order to prevent the carcinogenic effect of it. The aim of this article is the utilization of synthetic resins for decreasing high concentration of arsenic in water bodies. Monoplus M600, Lewatit FO36, Lewatit Sybron Ionac SR7 and Selion ASRFG3300 anion exchange resins were used for the removal of arsenic. The effects of the physicochemical parameters; reaction time, initial arsenic concentration, $\mathrm{pH}$ and ion exchange resin amount on arsenic sorption were investigated. The optimum resin amounts were found to be $60 \mathrm{mg}$ for Lewatit Monoplus M600 and Lewatit Sybron Ionac SR7 whereas it was 40 mg for Lewatit FO36 and Selion ASRFG3300. Lewatit FO36, Lewatit Monoplus M600 and Lewatit Sybron Ionac SR7 resins matched pseudo-first order model while Selion ASRFG3300 matched pseudo-second order model. Adsorption of all resins fit monolayer Langmuir adsorption isotherm. Maximum adsorption capacities $\left(\mathrm{Q}_{0}\right.$ values) of the two resins with iron oxide structure were found to be higher than the other two resins. The removal rates between $100 \mu \mathrm{g} / \mathrm{L}$ arsenic solution and surface water varied due to the matrix effect of the surface water. Treatment with ion exchange resins decreases the cytotoxic properties of arsenic on human colorectal epithelium cell.
\end{abstract}

Keywords: Arsenic; Ion Exchange; Isotherm; Kinetics; Colon Cancer

important metals in water is arsenic. Organic arsenic species are mostly encountered in the shellfish whereas more toxic inorganic arsenic species get involved in the drinking water by the dissolution of geological formations or as a result of the anthropogenic sources [1, 2]. Trace concentrations of arsenic is vital for hamsters, goats and chickens however, according to the determinations of IARC (International Agency for Research on Cancer), with the increase of the concentration it becomes toxic and carcinogenic [3-6]. Due to these hazardous effects, 
maximum allowable concentration of arsenic in drinking waters is limited to $10 \mu \mathrm{g} / \mathrm{L}$ by WHO (World Health Organization) and USEPA (United States Environmental Protection Agency).

In the cases of having not enough arsenic-free water in hand, arsenic-rich water must be treated for the use of the public. The treatment methods commonly used for the removal of arsenic are chemical precipitation, adsorption, ion exchange and membrane systems. lon exchange method is superior to the other treatment methods because of its low operating costs, low energy requirements and also regenerability of the ion exchange resins. However, because of the existence and high concentrations of other anions, arsenic removal may result with lower rates than expected.

After cardiovascular diseases, the main cause of death is cancer [7]. According to the 2012 data, colorectal cancer (CRC) remains a major health problem leading to over 700000 deaths worldwide [8]. Increased level of CRC is associated with bad nutrition habits, smoking, intestinal inflammatory disease, and environmental pollutants. Increased arsenic consumption causes decreased mitochondrial pathways and energy production due to its interaction with a-ketoglutarate [9].

In this study, selected ion exchange resins were characterized and utilized for arsenic removal in order to investigate the adsorption capacity with varying reaction time, initial arsenic concentration, $\mathrm{pH}$ and ion exchange resin amount. Fitness of the adsorptions to Langmuir and Freundlich adsorption isotherms and fitness of the kinetic to pseudo-first order and pseudo-second order kinetic equations were studied.

\section{Materials and Methods}

\section{Chemicals and solutions}

Anion exchange resins Lewatit FO36, Selion ASRFG3300, Lewatit Monoplus M600 and Lewatit Sybron Ionac SR7 were used. Lewatit Monoplus M600 is a strongly basic anion exchange resin while the others are weakly basic resins. Lewatit FO36 and Selion ASRFG3300 carry ferric oxide groups in their structure. Functional groups of the resins before and after arsenic sorption were analyzed by FT-IR (Fourier Transform Infrared Spectrophotometer-Perkin Elmer 100 FT-IR spectrophotometer, ATR).

Arsenic solutions were prepared by appropriate dilutions of Merck 1000 mg/L arsenate solution. Nitric acid (HNO3) and sodium hydroxide $(\mathrm{NaOH})$ were of analytical grade and obtained from Merck Co. All aqueous solutions and dilutions were made with ultra-pure water purified with Millipore Direct-Q.

\section{Determination of arsenic}

Arsenic analyses were made by Agilent 7500a model ICP-MS instrument. Calibration range for arsenic was $0.01 \mu \mathrm{g} / \mathrm{L}$ to 50 $\mu \mathrm{g} / \mathrm{L}$ with a correlation coefficient of 0.99977 . Limit of detection of the instrument according to method EPA 200.8 was found to be $0.2 \mu \mathrm{g} / \mathrm{L}$.

\section{Adsorption experiments}

Adsorption experiments were carried according to batch sorption technique. Initial arsenic concentration was $100 \mu \mathrm{g} / \mathrm{L}$ that is 10-fold of the maximum acceptable arsenic concentration and a probable concentration that can be met at any of the surface water in Nigde, Nevsehir or Aksaray cities of Turkey. Varying amounts of ion exchange resins were mixed with 50 $\mathrm{mL}$ arsenic solutions in shaker. The effect of ion exchange resin amount on arsenic sorption was studied and optimum amount of each ion exchange resin at specified conditions was determined. Surface water that is collected from Selime-Aksaray (Turkey) was used for the evaluation of arsenic sorption by the optimum resin amounts. Because of the matrix effect and possible arsenic forms contained in the surface water, lower arsenic sorption results were obtained.

Then the effect of initial arsenic concentration on the arsenic sorption was investigated. The arsenic removal data obtained from the results of ICP-MS after the sorption were used in order to investigate the fitness of the sorption to Langmuir and Freundlich isotherms. The arsenic removal \% and equilibrium adsorption capacity $\left(q_{e}\right)$ were calculated from Equations 1 and 2.

Sorption $\%=\frac{C_{0}-C_{e}}{C_{0}} * 100$

$q_{e}=\frac{\left(C_{0}-C_{e}\right) * V}{W}$

Where $C_{0}$ and $C_{e}$ are the initial and equilibrium concentrations of arsenic in $\mu \mathrm{g} / \mathrm{L}, V$ is volume the solution (L) and $W$ is the amount of ion exchange resin (mg). Equilibrium adsorption capacity, $q_{e}$ is the amount of arsenic adsorbed by one-milligram resin.

Adsorption isotherms are numeric expressions that describe the relationship between the amount of adsorbent and adsorbed contaminant concentration at a definite temperature. Two commonly applied adsorption isotherms are Langmuir and Freundlich isotherms $[10,11]$. 
Langmuir adsorption isotherm is the adsorption model that defends the monolayer coverage onto homogenous surface, however Freundlich adsorption that is the derived from Langmuir adsorption model defends the multilayer coverage onto heterogeneous surfaces [11, 12]. Langmuir adsorption isotherm is expressed by Equation 3 or by its linearized form as in Equation 4, respectively. Freundlich adsorption isotherm is expressed by Equation 5 and the linearized form of Freundlich adsorption isotherm is given in Equation 6.

$$
\begin{aligned}
& q_{e}=Q_{0} \frac{b C_{e}}{1+b C_{e}} \\
& \frac{C_{e}}{q_{e}}=\frac{1}{Q_{0} b}+\frac{C_{e}}{Q_{0}} \\
& q_{e}=k C_{e}^{1 / n}
\end{aligned}
$$

$$
\log q_{e}=\log k+\frac{1}{n} \log C_{e}
$$

Where $Q_{0}$ is the monolayer adsorption capacity ( $\mu \mathrm{g}$-arsenic/ mg-resin), $b$ is the selectivity constant (L-solution/ $\mu$ g-arsenic), $k$ is multilayer adsorption capacity ( $\mu \mathrm{g}$-arsenic/mg-resin) and $n$ is heterogeneity factor (mg-resin/L-solution) [12].

According to Equation 4, by using the slope and intercept of the plot of $C_{e} / q_{e}$ versus $C_{e^{\prime}} Q_{0}$ and $b$ can be calculated and according to Equation 6, the slope and intercept of the plot of $\log q_{e}$ versus $\log C_{e}$ give way to the calculation of the constants $k$ and $n$.

The convenience of the studied adsorption to the Langmuir adsorption isotherm is evaluated by the calculation of dimensionless $R_{L}$ as given in Equation 7. If $R_{L}$ value is between 0 and 1 , the adsorption is said to be convenient to Langmuir adsorption isotherm $[13,14]$. If $n$ value of the Freundlich isotherm model is greater than 1, the adsorption is said to be convenient to Freundlich adsorption isotherm [15]. Regression analysis is used in order to decide which adsorption best fits the studied adsorption [12].

$$
R_{L}=\frac{1}{1+b C_{0}}
$$

\section{Kinetic experiments}

In this batch study, kinetic experiments were carried out by mixing the optimum amounts of ion exchange resins with 50 $\mathrm{mL}$ of $100 \mu \mathrm{g} / \mathrm{L}$ arsenic solution for varying reaction times and optimum reaction time was determined. By using the experimental data, arsenic sorption of the ion exchange resins were investigated according to pseudo-first order and pseudo-second order kinetic models. Kinetic experiments are necessary studies that must be done during the adsorption processes since it gives information about the efficiency and rate of the reaction. Pseudo-first order and pseudo-second order kinetic models are the most commonly used adsorption kinetic models in the batch studies $[16,17]$.

Pseudo-first order model of Lagergren is expressed by Equation 8 or its linearized form as in Equation 9 [18].

$\frac{d q_{t}}{d t}=k_{1}\left(q_{e}-q_{t}\right)$

$\log \left(q_{e}-q_{t}\right)=\log q_{e}-\frac{k_{1} t}{2,303}$

Where $q_{t}$ is the adsorption capacity at time $t$ ( $\mu$ g-arsenic/ mg-resin) and $k_{1}$ is the pseudo-first order rate constant (1/ min). According to Equation 9, by using the plot of $\log \left(q_{e}-q_{\mathrm{t}}\right)$ versus $t, k_{1}$ is calculated from the slope and $q_{e}$ is calculated from the intercept. The proximity of calculated $q_{e}$ to the experimental $q_{e}$ is a measure of the fitness of the studied adsorption kinetic to pseudo-first order kinetic model [19].

Pseudo-second order model that is most appropriate for chemisorption process is expressed by Equation 10 or its linearized form as in Equation 11.

$\frac{d q_{t}}{d t}=k_{2}\left(q_{e}-q_{t}\right)^{2}$

$\frac{t}{q_{t}}=\frac{1}{k_{2} q_{e}^{2}}+\frac{t}{q_{e}}$

Where $k_{2}$ is the pseudo-second order rate constant (g.mg-1. min-1). The plot of $t / q_{t}$ versus $t$ as in Equation 11 is used to calculate $k_{2}$ from the intercept and $q_{e}$ from the slope. The closeness of calculated $q_{e}$ to the experimental $q_{e}$ is a measure of the acceptability of the studied adsorption kinetic as pseudo-first order kinetic model [19].

\section{Cell culture studies}

Since the absorption of the drinking water in the body occurs at intestine, cell culture studies were made on human colon epithelial cell, CCD-18Co. CCD-18Co was obtained from ATCC 
(American Type Culture Collection). Cells were grown in EMEM growth medium with $10 \% \mathrm{FBS}$ and $2 \mathrm{mM} \mathrm{L-glutamine}$ at $37^{\circ} \mathrm{C}$. Stock arsenic solutions were diluted with medium at appropriate ratios and varying dosages of arsenic were applied to colorectal cells and incubated for 48 hours. Cytotoxicity studies and cell viability tests were made with Alamar blue reactant by Elisa reader at $620 \mathrm{~nm}$ and $680 \mathrm{~nm}$. Inhibition of cell viability was analyzed with GraphPad Prism 5.0 software and IC50 value was calculated from sigmoidal plot [20].

\section{Results and Discussion}

\section{Effect of resin amount on arsenic sorption}

Each resin with varying amounts ranging from $10 \mathrm{mg}$ to 100 mg was mixed with $50 \mathrm{~mL}$ of $100 \mu \mathrm{g} / \mathrm{L}$ arsenic solution. After mixing for a definite period, the samples were filtrated to analyze the arsenic concentration by ICP-MS instrument. Arsenic sorption percentages were calculated by Equation 12 .

Sorption percentage $\%=\frac{C_{0}-C_{e}}{C_{0}} * 100$

Where $C_{0}$ and $C_{e}$ are the initial and equilibrium arsenic concentrations respectively.

Figure 1 shows the effect of ion exchange resin amount on arsenic sorption. By the increase of resin amount, the sorption also increases. The resin amount of the plateau value is taken as the optimum resin amount since after the plateau, the increase of the resin amount does not further affect the sorption percentage.

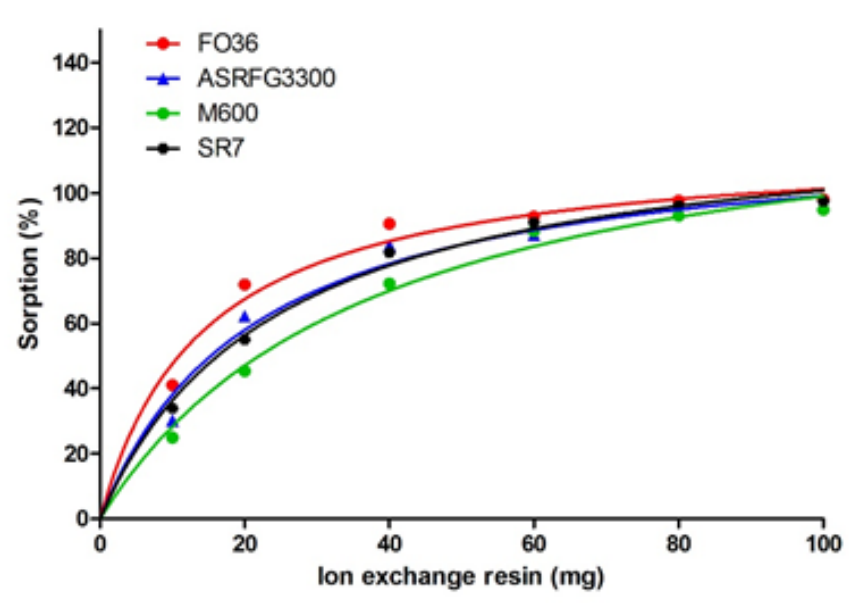

Figure 1: The effect of resin amount on arsenic sorption.

For the determined conditions, the optimum resin amounts for Lewatit Monoplus M600 and Lewatit Sybron Ionac SR7 were determined to be $60 \mathrm{mg}$ whereas they were found to be 40 mg for Lewatit FO36 and Selion ASRFG3300.

The optimum amount of each resin was applied to $50 \mathrm{~mL}$ surface water containing $57.61 \mu \mathrm{g} / \mathrm{L}$ arsenic and in Figure 2 the sorption percentages were given as a comparison with 100 $\mu \mathrm{g} / \mathrm{L}$ arsenic solution. The cause of arsenic sorption decrease of surface water when compared with $100 \mu \mathrm{g} / \mathrm{L}$ arsenic solution is the matrix effect of the surface water beside the effect of existence of different arsenic forms in the surface water. The surface water contains competitive anions like $41.49 \mathrm{mg} / \mathrm{L}$ sulfate and $16.51 \mathrm{mg} / \mathrm{L}$ nitrate besides trivalent arsenic that is harder to remove by ion exchange resins.

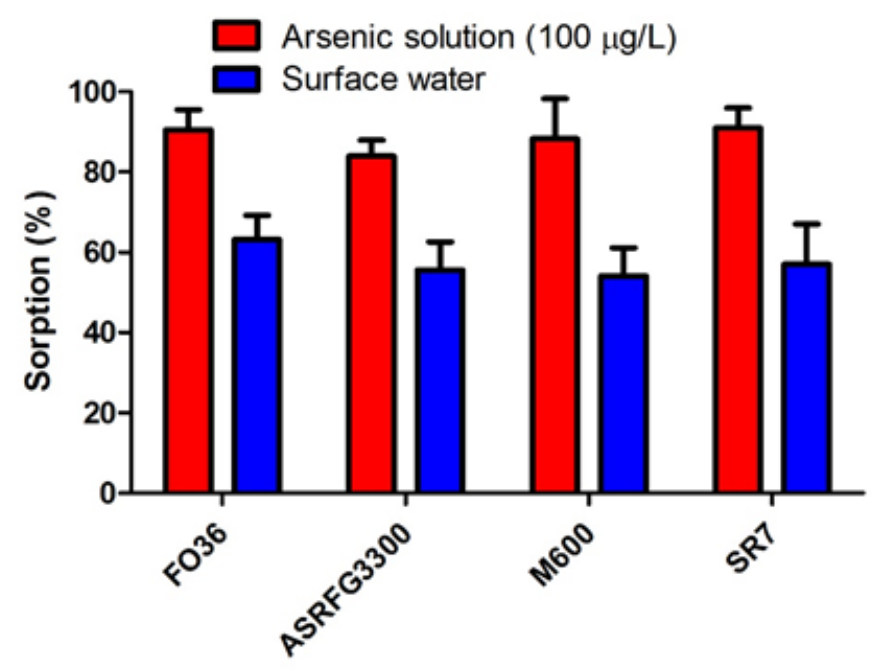

Figure 2: Arsenic sorption of $100 \mu \mathrm{g} / \mathrm{L}$ arsenic solution and surface water by ion exchange resins.

\section{Effect of reaction time on arsenic sorption}

$50 \mathrm{ml}$ of $100 \mu \mathrm{g} / \mathrm{L}$ arsenic solutions were mixed with optimum ion exchange resin amounts for reaction times ranging from 5 to 90 minutes and at the end of the reaction the filtered samples were analyzed and the sorption capacities as a function of time were given in Figure 3. In the Figure, $q_{t}$ gives the sorption capacity ( $\mu \mathrm{g}$-As/mg-resin) at a given time t. The sorption capacity is calculated by Equation 13 where $C_{0}$ and $C_{e}$ are the initial and equilibrium arsenic concentrations respectively, $V$ $(\mathrm{L})$ is the volume of the solution and $W(\mathrm{mg})$ is the mass of ion exchange resin.

$q_{e}=\frac{\left(C_{0}-C_{e}\right) V}{W}$ 


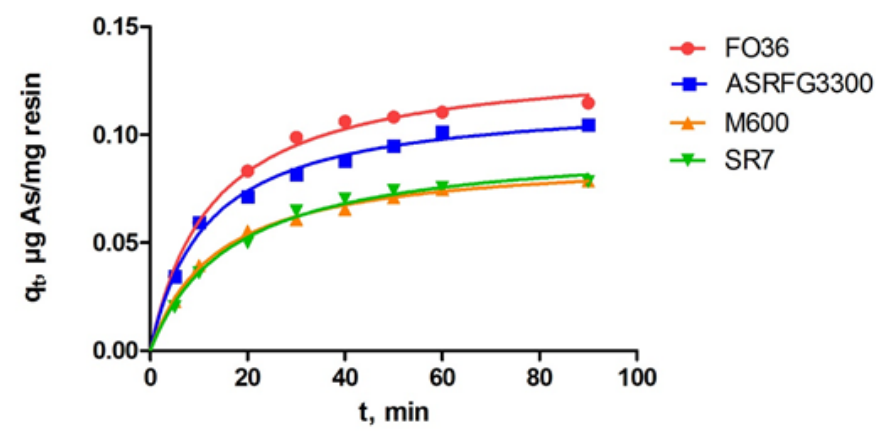

According to Figure 3, by the increase of the reaction time sorption capacity arrives at a value that does not change any more with the increase of time. Optimum reaction time at the plateau values were taken as 50 minutes for all resins.

Arsenic sorption of ion exchange resins was evaluated by the pseudo-first order and pseudo-second order kinetic models according to Equations 9 and 11. The pseudo-first order and pseudo-second order kinetic parameters are given on Table 1.

Figure 3: Effect of reaction time on arsenic sorption.

Table 1: Pseudo-first order and pseudo-second order kinetic parameters for arsenic sorption of resins.

\begin{tabular}{|c|c|c|c|c|c|c|c|}
\hline \multirow[b]{2}{*}{ Anion exchange resin } & \multirow{2}{*}{ 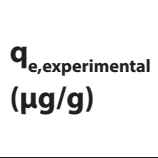 } & \multicolumn{3}{|c|}{ Pseudo-first order } & \multicolumn{3}{|c|}{ Pseudo-second order } \\
\hline & & $\begin{array}{l}q_{e, \text { calculated }} \\
(\mu \mathrm{g} / \mathrm{g})\end{array}$ & $K_{1}(1 / d k)$ & $\mathbf{R}_{2}$ & $\begin{array}{l}q_{e, \text { calculated }} \\
(\mu \mathrm{g} / \mathrm{g})\end{array}$ & $k_{2}(g / m g \cdot d k)$ & $\mathbf{R}_{2}$ \\
\hline Lewatit FO 36 & 108.174 & 142.56 & 0.100 & 0.9702 & 150.07 & 0.415 & 0.9980 \\
\hline Selion ASR3300FG & 94.916 & 73.38 & 0.058 & 0.9888 & 109.36 & 0.914 & 0.9955 \\
\hline Lewatit Monoplus M600 & 71.068 & 59.58 & 0.060 & 0.9904 & 87.34 & 0.894 & 0.9951 \\
\hline Lewatit Sybron Ionac SR7 & 74.128 & 85.86 & 0.075 & 0.9824 & 108.14 & 0.434 & 0.9913 \\
\hline
\end{tabular}

In order to decide the kinetic mechanism of the adsorption, the closeness of $q_{e, \text { experimental }}$ values with $q_{e, \text { calculated }}$ values of pseudo-first order and pseudo-second order kinetic models were evaluated and the convenience to the kinetic model must also be supported by the correlation coefficients. Lewatit FO36, Lewatit Monoplus M600 and Lewatit Sybron Ionac SR7 resins are convenient with pseudo-first order model which addresses to physisorption while Selion ASR3300FG is convenient with pseudo-second order model that addresses chemisorption.

\section{Effect of pH on arsenic sorption}

The determined optimum amounts of each resin were mixed with $50 \mathrm{~mL} 100 \mu \mathrm{g} / \mathrm{L}$ arsenic solution for 50 minutes at varying $\mathrm{pH}$ ranges, and in order to find the optimum $\mathrm{pH}$ of the sorption reaction varying ranges of $\mathrm{pH}$ from 2 to 7 were supplied by the addition of $0.1 \mathrm{M} \mathrm{HNO} 3$ or $0.1 \mathrm{M} \mathrm{NaOH}$ solutions. At the end of the reaction time, the samples were filtered and analyzed by ICP-MS and the effect of $\mathrm{pH}$ on the sorption was given in Figure 4. The sorption percentages of strongly basic ion exchange resin Lewatit Monoplus M600 was not affected by the $\mathrm{pH}$ changes however weakly basic ion exchange resins (Lewatit FO36, Selion ASR3300FG and Lewatit Sybron Ionac SR7) were significantly affected by the $\mathrm{pH}$ changes. Optimum $\mathrm{pH}$ values of arsenic sorption at the determined conditions for Lewatit FO36, Selion ASR3300FG, Lewatit Monoplus M600 and
Lewatit Sybron lonac SR7 are 4.41, 4.69, 4.00 and 5.71 respectively.

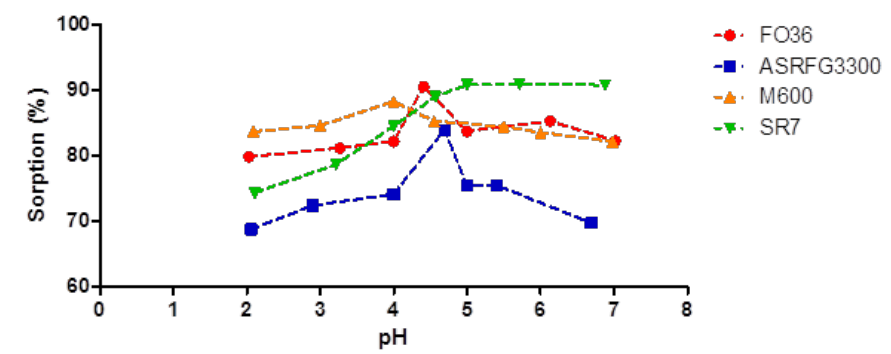

Figure 4: Arsenic sorption at different $\mathrm{pH}$ values.

\section{Effect of initial arsenic concentration on arsenic sorption}

Varying concentrations of arsenic were prepared by the dilution of the stock solution. $50 \mathrm{~mL}$ of arsenic solutions ranging from $100 \mu \mathrm{g} / \mathrm{L}$ to $2 \mathrm{mg} / \mathrm{L}$ were mixed with optimum amounts of each resin at optimum $\mathrm{pH}$ values for 50 minutes. At the end, the solutions were filtered and analyzed by ICP-MS and in Figure 5, arsenic sorptions for one milligram of resin against equilibrium arsenic concentrations were given. Using the sorption data and Equations 4, 6 and 7, convenience of the sorption to Freundlich and Langmuir sorption isotherms were evaluated and Table 2 was prepared. 


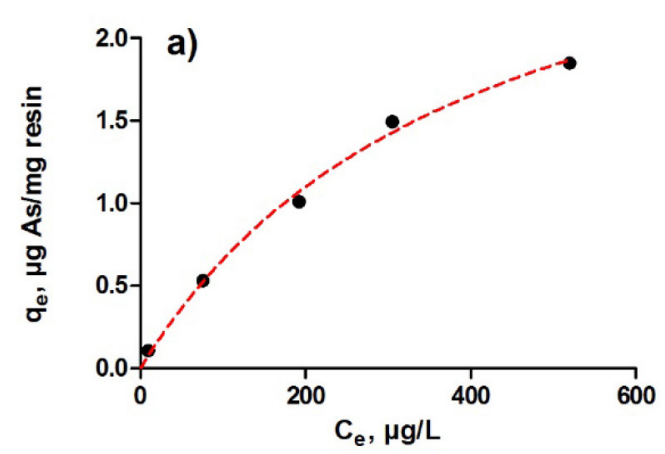

c)

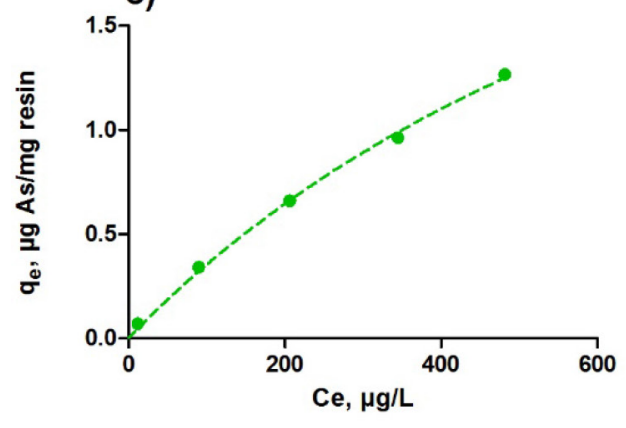

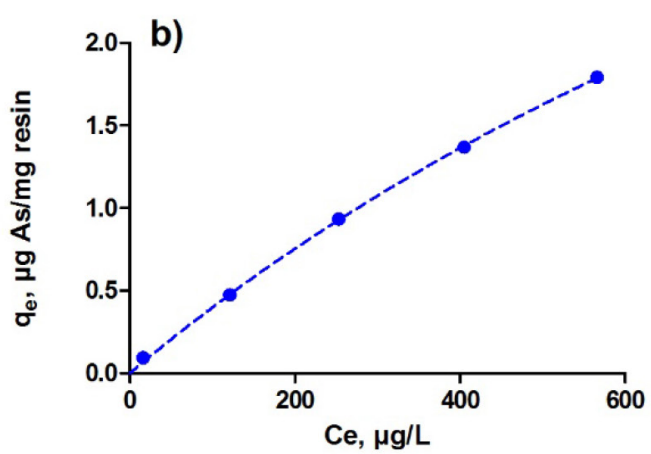

d)

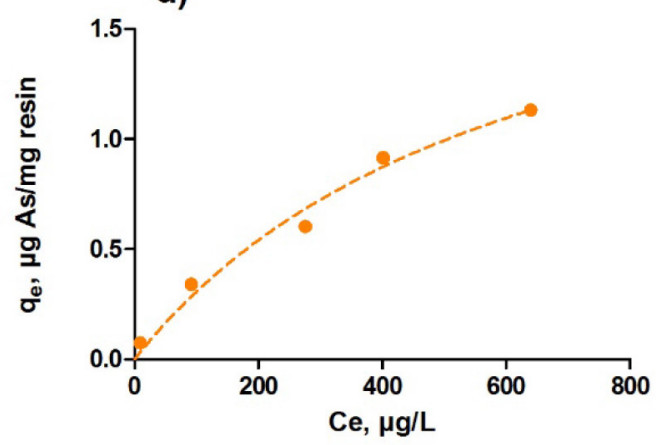

Figure 5: Arsenic sorptions for one milligram of resin against equilibrium arsenic concentrations.

Table 2: Freundlich and Langmuir isotherm constants.

\begin{tabular}{|c|c|c|c|c|c|c|c|}
\hline \multirow{2}{*}{ Ion exchange resin } & \multicolumn{3}{|c|}{ Freundlich isotherm } & \multicolumn{4}{|c|}{ Langmuir isotherm } \\
\hline & $n(\mathrm{mg} / \mathrm{L})$ & k ( $\mu \mathrm{g} / \mathrm{mg})$ & $\mathbf{R 2}$ & $\begin{array}{c}\text { b } \\
(L / \mu g)\end{array}$ & $\mathrm{QO}(\mu \mathrm{g} / \mathrm{mg})$ & $\mathbf{R L}$ & R2 \\
\hline Lewatit FO 36 & 1.26 & 0.02 & 0.9899 & 0.0025 & 3.297 & 0.80 & 0.9858 \\
\hline Selion ASR3300FG & 1.07 & 0.01 & 0.9982 & 0.0005 & 8.177 & 0.95 & 0.9737 \\
\hline Lewatit Monoplus M600 & 1.21 & 0.01 & 0.9991 & 0.0016 & 2.759 & 0.86 & 0.9426 \\
\hline Lewatit Sybron lonac SR7 & 1.48 & 0.01 & 0.9955 & 0.0031 & 1.610 & 0.76 & 0.8905 \\
\hline
\end{tabular}

Since $n$ values of the resins are greater than 1, adsorptions are said to be convenient to Freundlich isotherm and since $R_{L}$ values are between 0 and 1 , adsorptions are said to be convenient to Langmuir isotherm. When the correlation coefficients are compared, it is found that adsorption with Lewatit FO36, Selion ASR3300FG, Lewatit Monoplus M600 and Lewatit Sybron lonac SR7 fit monolayer Langmuir adsorption isotherm.

The monolayer adsorption capacity $Q_{0}$ was found to be ranging from $1.508 \mu \mathrm{g} / \mathrm{mg}$ to $8.177 \mu \mathrm{g} / \mathrm{mg}$. Since realistic studies were made by the choice of initial arsenic concentrations, adsorption capacities were found to be lower when compared with other literatures.

\section{Characterization of the resins before and after arsenic sorption}

Characterization of the ion exchange resins before and after arsenic sorption are given in Figure 6. Virgin resins are defined by the $\mathrm{O}-\mathrm{H}$ stretching vibration band of the adsorbed water around $3262 \mathrm{~cm}^{-1}$ to $3356 \mathrm{~cm}^{-1}, \mathrm{C}-\mathrm{H}$ stretching vibration band around $2925 \mathrm{~cm}^{-1}$ to $2930 \mathrm{~cm}^{-1}$ that may be attributed to the polystyrene structure of the resins and $\mathrm{C}-\mathrm{H}$ symmetric bending vibration band around $1464 \mathrm{~cm}^{-1}$ to $1482 \mathrm{~cm}^{-1}$ that may 
be attributed to quaternary amine groups of the resins [2123]. O-H asymmetric stretching vibration and Fe-O stretching vibration at $1083 \mathrm{~cm}^{-1}$ to $1095 \mathrm{~cm}^{-1}$ and $532 \mathrm{~cm}^{-1}$ to $561 \mathrm{~cm}^{-1}$ bands respectively reveal at the FTIR analysis of Lewatit FO36 and Selion ASR3300FG resins [24]. After the sorption of arsenic on the ion exchange resins, the bands of $\mathrm{O}-\mathrm{H}$ stretching vibration and $\mathrm{C}=\mathrm{C}$ stretching vibration shifted and gave smaller peaks while the As-O peaks came in sight around $848 \mathrm{~cm}^{-1}$ to $888 \mathrm{~cm}^{-1}$ [25-27].

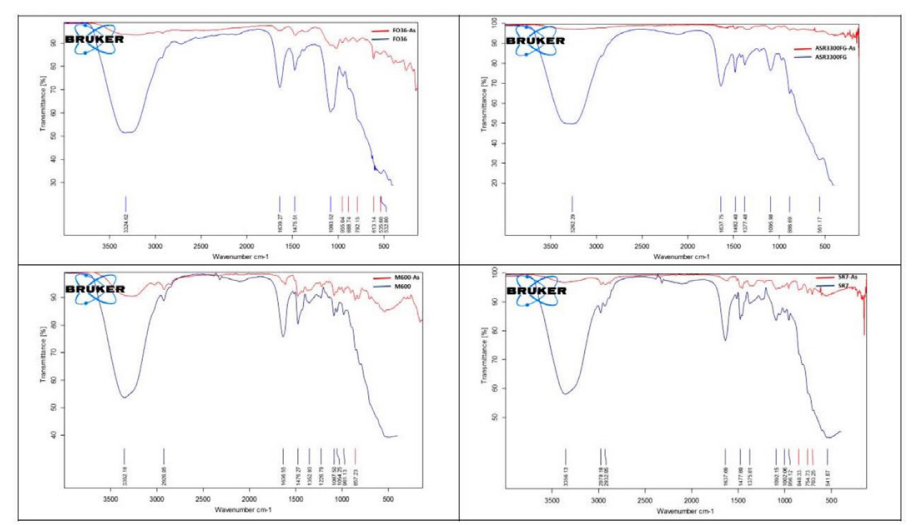

Figure 6: FTIR analysis before and after arsenic sorption.

Relative cell viability graphs are given in Figure 7 shows that $100 \mu \mathrm{g} / \mathrm{L}$ arsenic solution causes cytotoxic effects, and inhibits the proliferation and viability of human colon epithelial cell, CCD-18Co. IC $\mathrm{I}_{50}$ value of arsenic solution was calculated as 65 ppb before treatment with resins, which was increased up to 3984 ppb after resin treatment. Post-treatment of arsenic solution with ion exchange resin prevents arsenic toxicity on human colon epithelial cell, CCD-18Co. Besides, Arsenic solution also gradually suppressed the growth of the human CRC cells; SW480, SW/As, DLD-1, and COLO201 in a concentration-dependent manner [28].
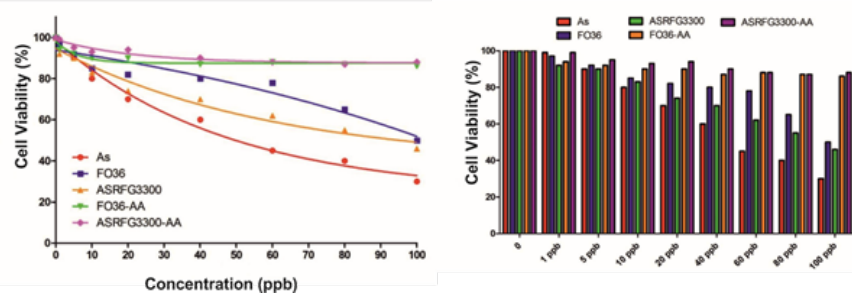

Figure 7: Effects of resins against arsenic toxicity on human colon cell.

\section{Conclusion}

Since the occurrence of arsenic in water is in the anionic form, four anion exchange resins were utilized for the removal of arsenic from $100 \mu \mathrm{g} / \mathrm{L}$ solution and from a real surface water. At the end of the isotherm studies, Lewatit FO 36, Lewatit Monoplus M600 and Lewatit Sybron Ionac SR7 resins were found to follow the pseudo-first order kinetic model whereas Selion ASR3300FG followed the pseudo-second order kinetic model that addresses a chelation reaction of the functional groups with arsenate ions. Arsenic adsorption percentages of strongly basic anion exchange resin Lewatit Monoplus M600 was not affected by the $\mathrm{pH}$ changes whereas weakly basic anion exchange resins showed oscillations at the $\mathrm{pH}$-sorption graph. All ion exchange resins obeyed the monolayer Langmuir adsorption isotherm. Maximum adsorption capacities (Q0 values) of the resins Selion ASR3300FG and Lewatit FO36 were found to be higher than the others, due to the included iron oxide structure. Iron oxide structure of these two resins also supplied smaller differences between the adsorption rates of $100 \mu \mathrm{g} / \mathrm{L}$ arsenic solution and surface water. lon-exchange resins decrease cytotoxic potential of arsenic on human colorectal epithelium cells. This property of resins makes them valuable molecules against arsenic toxicity.

\section{References}

1. Chatterjee D, Haider D, Majumder S, Biswas A, Nath B, Bhattacharya P, et al. (2010) Assessment of arsenic exposure from groundwater and rice in Bengal delta region, West Bengal, India. Water Res 44(19): 5803-5812.

2. Yamaguchi N, Ohkura T, Takahashi Y, Maejima Y, Arao T (2014) Arsenic distribution and speciation near rice roots influenced by iron plaques and redox conditions of the soil matrix. Environ Sci Tech 48(3): 1549-1556.

3. Clark RM (1987) Technological approaches to removing toxic contaminants. Water Eng Res EPA 815-828.

4. Ezedom T and Asagba SO (2016) Effect of a controlled food-chain mediated exposure to cadmium and arsenic on oxidative enzymes in the tissues of rats. Toxicol Rep 3: 708-715.

5. Gunduz O, Bakar C, Simsek C, Baba A, Elci A, Gurleyuk H, et al. (2017) The health risk associated with chronic diseases in villages with high arsenic levels in drinking water supplies. Expo Health 9: 261-273.

6. Westerhoff $P$ (2006) Arsenic removal with agglomerated nanoparticle media. AWWA Research Foundation. 1-88.

7. WHO (2008) Are the number of cancer cases increasing or decreasing in the world? In. 
8. Sarkar S, Horn G, Moulton K, Oza A, Byler S, Kokolus S, et al. (2013) Cancer development, progression, and therapy: An epigenetic overview. Int J Mol Sci 14(10): 21087-21113.

9. Tan Z, Zhang XL, Kang T, Zhang L, Chen SY (2018) Arsenic sulfide amplifies JQ1 toxicity via mitochondrial pathway in gastric and colon cancer cells. Drug Des Dev Ther 12: 3913-3927.

10. Ali J, Tuzen M, Kazi TG, Hazer B (2016) Inorganic arsenic speciation in water samples by miniaturized solid phase microextraction using a new polystyrene polydimethyl siloxane polymer in micropipette tip of syringe system. Talanta 161: 450-458.

11. Clifford D and Lin CC (1995) lon exchange, activated alumina, and membrane processes for arsenic removal from groundwater. In proceedings of the 45th Annual Environmental Engineering Conference, (University of Kansas).

12. Borgnino L, Avena MJ, De Pauli CP (2009) Synthesis and characterization of Fe(III)-montmorillonites for phosphate adsorption. Colloids Surf A 341: 46-52.

13. Toroz I, Sawyer CN, McCarty PL, Parkin GF (2003) Chemistry for environmental engineering and science 5th ed. McGraw-Hill Education, NY, USA.

14. Hazardous materials and waste water:Treatment, removal and analysis. Lewinsky AA, editor. New York: Nova Science Publishers, Inc., c2007.

15. Livingston JV (2005) Trends in Water Pollution Research Nova Science Pub Inc.

16. Bonilla-Petriciolet A, Mendoza-Castillo DI, Reynel-Avila HE (2017) Adsorption processes for water treatment and purification: Springer International Publishing.

17. Dotto GL, Campana-Filho SP, de Almeida Pinto LA (2017) Frontiers in Biomaterials: Chitosan based materials and its applications. Bentham Science Publishers, p: 334.

18. Lagergren S (1898) About the theory of so-called adsorption of soluble substances. Royal Swedish Academy of Sciences Documents 24: 1-39.

19. Bhadusha N and Ananthabaskaran T (2012) Kinetic, thermodynamic and equilibrium studies on uptake of rhodamine $\mathrm{B}$ onto $\mathrm{ZnCl} 2$ activated low cost carbon. E-J Chem 9(1): 137-144.
20. Karakurt S and Adali O (2016) Tannic acid inhibits proliferation, migration, invasion of prostate cancer and modulates drug metabolizing and antioxidant enzymes. Anti-Cancer Agents Med Chem 16(6): 781-789.

21. Jachula J, Kolodynska D, Hubick Z (2011) Sorption of $\mathrm{Cu}(\mathrm{II})$ and $\mathrm{Ni}(\mathrm{II})$ ions in the presence of the methyl glycine di-acetic acid by microporous ion exchangers and sorbents from aqueous solutions. J Chem 9(1): 52-65.

22. Tandorn S, Arquero O, Naksata W, Sooksamiti P (2017) Preparation of anion exchange resin loaded with ferric oxide for arsenic (V) removal from aqueous solution. Int J Environ Sci Dev 8(6): 399-403.

23. Xu ZM, Han DX, LiY, Zhang PL, You LJ, Zhao ZG (2018) High removal performance of a magnetic $\mathrm{FPA} 90-\mathrm{Cl}$ anion resin for bromate and coexisting precursors: Kinetics, thermodynamics, and equilibrium studies. Environ Sci Pol Res 25: 18001-18014.

24. Xiong Y, Tong Q, Shan WJ, Xing ZQ, Wang YJ, Wen S, et al. (2017) Arsenic transformation and adsorption by iron hydroxide/manganese dioxide doped straw activated carbon. Appl Sur Sci 416: 618-627.

25. Gupta A, Chauhan VS, Sankararamakrishnan N (2009) Preparation and evaluation of iron-chitosan composites for removal of As (III) and As (V) from arsenic contaminated real life groundwater. Water Res 43(15): 3862-3870.

26. Myneni SCB, Traina SJ, Waychunas GA, Logan TJ (1998) Experimental and theoretical vibrational spectroscopic evaluation of arsenate coordination in aqueous solutions, solids, and at mineral-water interfaces. Geochim Cosmochim Acta 62: 3285-3300.

27. Neto JDM, Bellato CR, Milagres JL, Pessoa KD, de Alvarenga ES (2013) Preparation and evaluation of chitosan beads immobilized with iron(III) for the removal of $\mathrm{As}(\mathrm{III})$ and As(V) from water. J Braz Chem Soc 24(1): 121-132.

28. Nakagawa Y, Akao Y, Morikawa H, Hirata I, Katsu K, Naoe T, et al. (2002) Arsenic trioxide-induced apoptosis through oxidative stress in cells of colon cancer cell lines. Life Sci 70(19): 2253-2269.

Copyright: $\odot 2019$ Karakurt S, et al. This is an open-access article distributed under the terms of the Creative Commons Attribution License, which permits unrestricted use, distribution, and reproduction in any medium, provided the original author and source are credited. 